\title{
PROPAGATION VELOCITY AND RATE OF ATTENUATION OF SURFACE WAVES ON A HOMOGENEOUSLY FLUIDIZED BED
}

\author{
J. B. W. KoK and A. A. J. BeNSCHOP \\ Department of Mechanical Engineering, University of Twente, P.O. Box 217, 7500 AE Enschede, \\ The Netherlands
}

(Received 15 October 1992; in revised form 30 November 1993)

\begin{abstract}
Surface waves with a frequency of $0.5-2.5 \mathrm{~Hz}$ were generated on a homogeneously fluidized bed. The propagation velocity and rate of attenuation of the induced pressure fluctuations were measured using signal averaging techniques. The measured wave velocity and attenuation rate correlated well with predictions based on a theory which considers the bed as an incompressible liquid with low viscosity. From the rate of attenuation an effective bed viscosity was calculated between 1.2 and $6.0 \mathrm{~Pa} \cdot \mathrm{s}$. At high frequencies the wave generator produced high-amplitude density waves.
\end{abstract}

Key Words: fluidized, waves, propagation, attenuation, viscosity, dispersive

\section{INTRODUCTION}

In heterogeneously fluidized beds periodic pressure fluctuations can be observed. Their amplitude is up to one-tenth of the bed pressure drop and their frequencies range from 1 to $10 \mathrm{~Hz}$. The pressure fluctuations induced by bubble motion have been studied extensively (Fan et al. 1983). Pressure fluctuations induced by surface waves have received only minor attention.

Rice \& Wilhelm (1958) conjectured that surface waves would propagate similarly to water waves. Using basic equations proposed by Anderson \& Jackson (1967), Needham (1984) formulated equations describing two-dimensional surface waves on a fluidized bed. By assuming a uniform particle concentration $(\alpha)$ and an incompressible fluidizing gas, Needham confirmed the fluidized bed/water surface wave analogy. The well-known results for the propagation of surface waves on water are summarized in the appendix.

To the knowledge of the authors, the only experimental verifications were reported as early as 1969 in Finnerty et al. (1969). They generated waves on the surface of a fluidized bed with a horizontally oscillating paddle. The paddle frequency was varied from 3 to $9 \mathrm{~Hz}$ and wavelengths were measured between 12 and $3 \mathrm{~cm}$. The wavelengths were measured from motion pictures. This simple equipment did not allow for the dispersive character of wave propagation and lacked the accuracy to measure the rate of attenuation of the surface waves. The effective fluidized bed viscosity could not be determined. Finnerty et al. (1969) found that for paddle frequencies ranging from 3 to $6 \mathrm{~Hz}$ there was reasonable agreement between the propagation speed predicted by the theory on water waves and the fluidized bed experiments.

In the present research, an accurate experimental verification of the water wave analogy for the case of moderate wavelengths with respect to propagation velocity and rate of attenuation is performed. With a wave generator suitable for the production of wavelengths of $2-0.5 \mathrm{~m}$ in a frequency range from 1 to $2 \mathrm{~Hz}$, waves were generated on a homogeneously fluidized bed. In view of the industrial applications, it is this frequency range that is interesting because pressure fluctuations due to long waves $(\lambda>0.5 \mathrm{~m})$ are present throughout the bed. The propagation velocity and rate of attenuation of the induced pressure fluctuations were determined with high accuracy by calculating the auto- and cross-spectral density functions. 


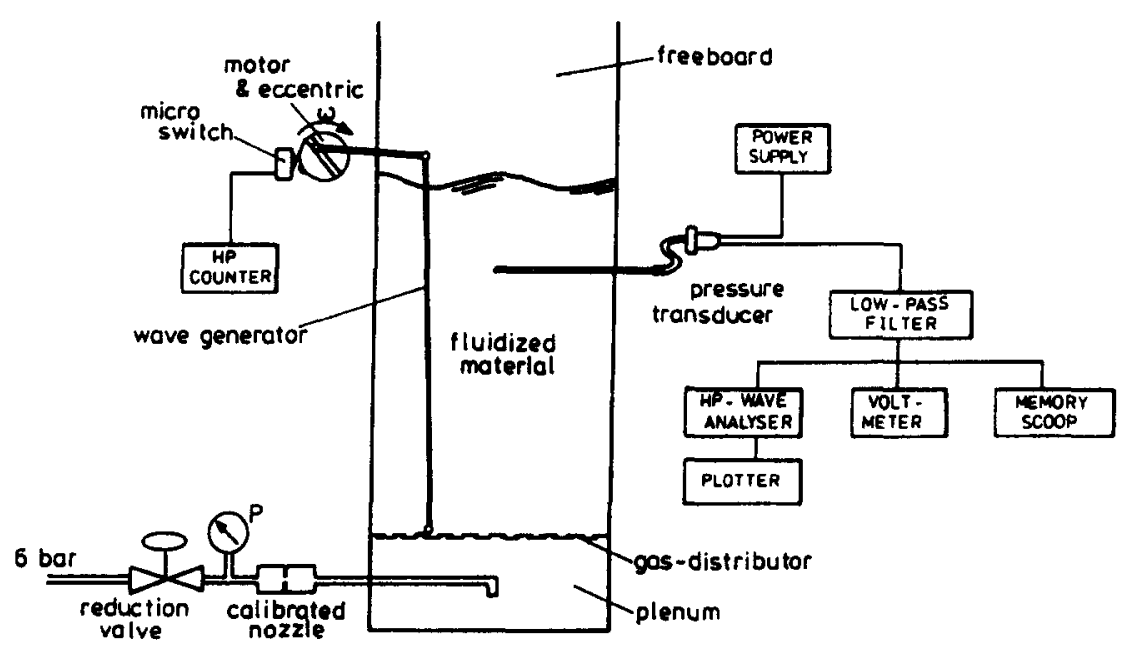

Figure 1. The experimental setup.

\section{EXPERIMENTAL SETUP}

A schematic view of the experimental setup is shown in figure 1. The fluidized bed assembly consisted of a bed column, a gas distributor and a plenum column. The bed and the plenum column were 2.0 and $0.5 \mathrm{~m}$ long, respectively, and had a square cross-section of $0.6 \times 0.6 \mathrm{~m}^{2}$. The gas distributor was a porous plate with a $4 \mathrm{kPa}$ pressure drop under operating conditions. The fluidization air was supplied to the plenum column from a pressure vessel via a pressure-reduction valve and a precalibrated nozzle.

The fluidized particles were polystyrene spheres (Shell Hostapor D unterkorn B 700). These specific Shell polystyrene particles could not be charged electrostatically. The size distribution was narrow, $90 \%$ had a diameter between 250 and $350 \mu \mathrm{m}$ and the bulk density was $620 \mathrm{~kg} / \mathrm{m}^{-3}$. The minimum fluidization velocity $\left(U_{\mathrm{m} f}\right)$ was $2.3 \mathrm{~cm} / \mathrm{s}$ and the minimum bubbling velocity $\left(U_{\mathrm{mb}}\right)$ was $2.6 \mathrm{~cm} / \mathrm{s}$. The bed was usually operated at $2.4 \mathrm{~cm} / \mathrm{s}$.

The wave generator consisted of a plate, hinged at the distributor $10 \mathrm{~cm}$ from the nearest wall. A bar linkage connected the upper end of the plate to an eccentric driven by an electromotor. The period was measured every revolution by a counter (HP 5315-A). According to Biésel \& Suquet $(1951 \mathrm{a}, \mathrm{b})$, this is a suitable type of generator for surface waves of moderate wavelengths.

Opposite the wave generator at $0.3 \mathrm{~m}$ above the distributor, two $0.5 \mathrm{~m}$ long tubes were inserted into the bed column. Each tube was connected to a pressure transducer (Viatran 219-15). The experiments were made with pressure tube openings located in one horizontal plane at horizontal distances of 20 and $30 \mathrm{~cm}$ from the neutral position of the wave generator. The two pressure transducer signals were sent to an HP 5432-A spectrum analyser via a dual low-pass filter. The analyser calculated the auto- and cross-correlation and auto- and cross-spectral density functions of the two pressure signals.

\section{METHOD OF ANALYSIS}

The goal was to obtain the time delay and decay in magnitude between two pressure fluctuation signals measured at different distances from the wave generator. In a conventional time delay analysis, the cross-correlation function $R_{x y}(\tau)$ is calculated from two signals, $x(t)$ and $y(t)$, using the expression

$$
R_{x y}(\tau)=\lim _{T \rightarrow \infty} \frac{1}{T} \int_{0}^{T} x(t) \cdot y(t+\tau) \mathrm{d} t .
$$

The time delay between the two signals is given by the value of $\tau$ at the first maximum of $R_{x y}(\tau)$. Reproducible results could not be obtained by this method. The time delay can be obtained accurately from $R_{x y}(\tau)$ if there is, at just one frequency, a periodic oscillation in the signal (Bendat 


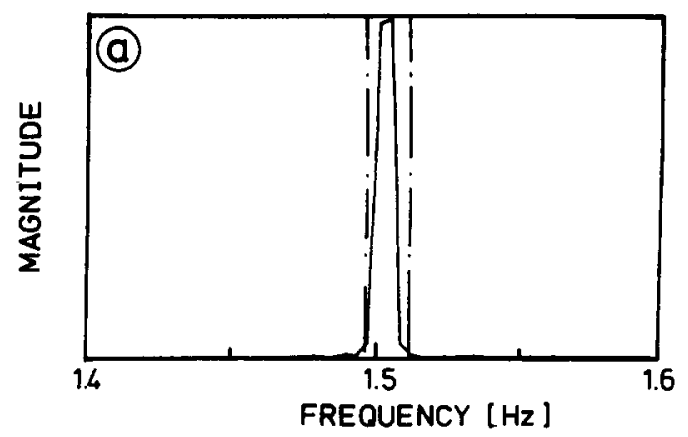

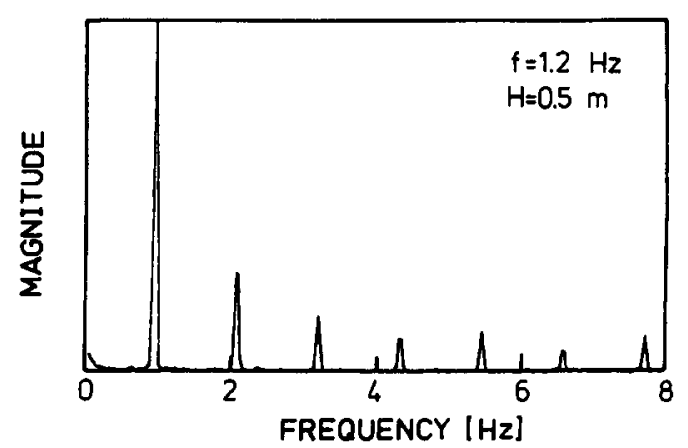

Figure 2. A representative auto-spectral density function of the pressure fluctuation signal.

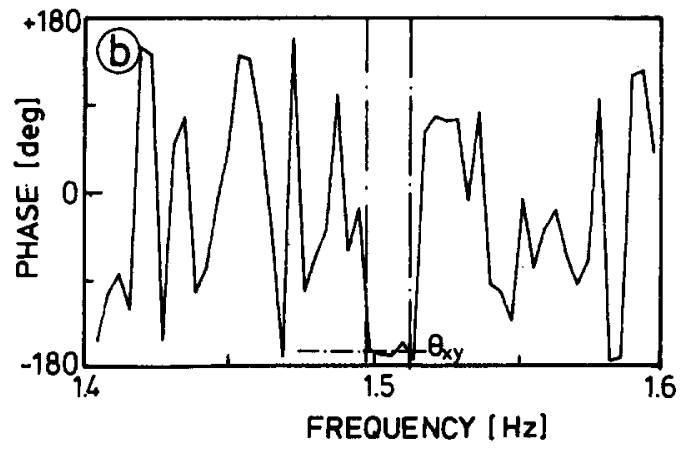

Figure 3. Magnitude and phase-shift angle of a typical cross-spectral density function of the pressure fluctuation signal.

\& Piersol 1980). In order to verify this, the auto-correlation function $R_{x x}(\tau)$ was calculated. This function is similar to $R_{x y}(\tau)$ with $y(t+\tau)$ replaced by $x(t+\tau)$. The Fourier transform of $R_{x x}(\tau)$ (auto-spectral density) shows the composition of the pressure signal. Figure 2 shows a representative auto-spectral density function $G_{x x}(f)$ of the measured pressure fluctuation signal. Peaks occur at the generator frequency and its harmonics.

Due to the dispersive propagation, in this case time delays have to be measured at each frequency component separately. This can be done by calculating the cross-spectral density function $G_{x y}(f)$. This is the Fourier transform of $R_{x y}(\tau) . G_{x y}(f)$ is a complex function and is usually expressed in terms of a magnitude and a phase-shift angle as a function of frequency:

$$
G_{x y}(f)=\left|G_{x y}(f)\right| \cdot \exp \left[-j \cdot \theta_{x y}(f)\right] \quad \text { with } j^{2}=-1 .
$$

The time delay $\tau(f)$, in seconds, between two signals at a specific frequency can be calculated from the phase-shift angle $\theta_{x y}(f)$ (Bendat \& Piersol 1980):

$$
\tau(f)=\frac{\theta_{x y}(f)}{360 \cdot f} .
$$

The propagation velocity is $V(f)=\Delta x / \tau(f) \mathrm{m} / \mathrm{s}$ (here $\Delta x=0.1 \mathrm{~m}$ ). A typical measured $G_{x y}(f)$ is given in figure 3. At the frequency interval at which the peak in $\left|G_{x y}\right|$ occurs, the calculated phase-shift angle is constant. Other frequency intervals contain noise only. With a view to accuracy, a bandwidth of $1 \mathrm{~Hz}$, centred at the wave generator frequency, was chosen.

The decay of the pressure fluctuation signal can be calculated for each frequency component from the function $G_{x x}(f)$ at two locations. The area covered by the peaks in $G_{x x}(f)$ is equal to the square of the pressure amplitude $P$ at the peak frequency. The logarithmic decrement in space is calculated by

$$
\mathrm{LD}_{x}=\frac{\ln \left[\frac{P(x)}{P(x+\Delta x)}\right]}{\Delta x} \mathrm{~m}^{-1}
$$




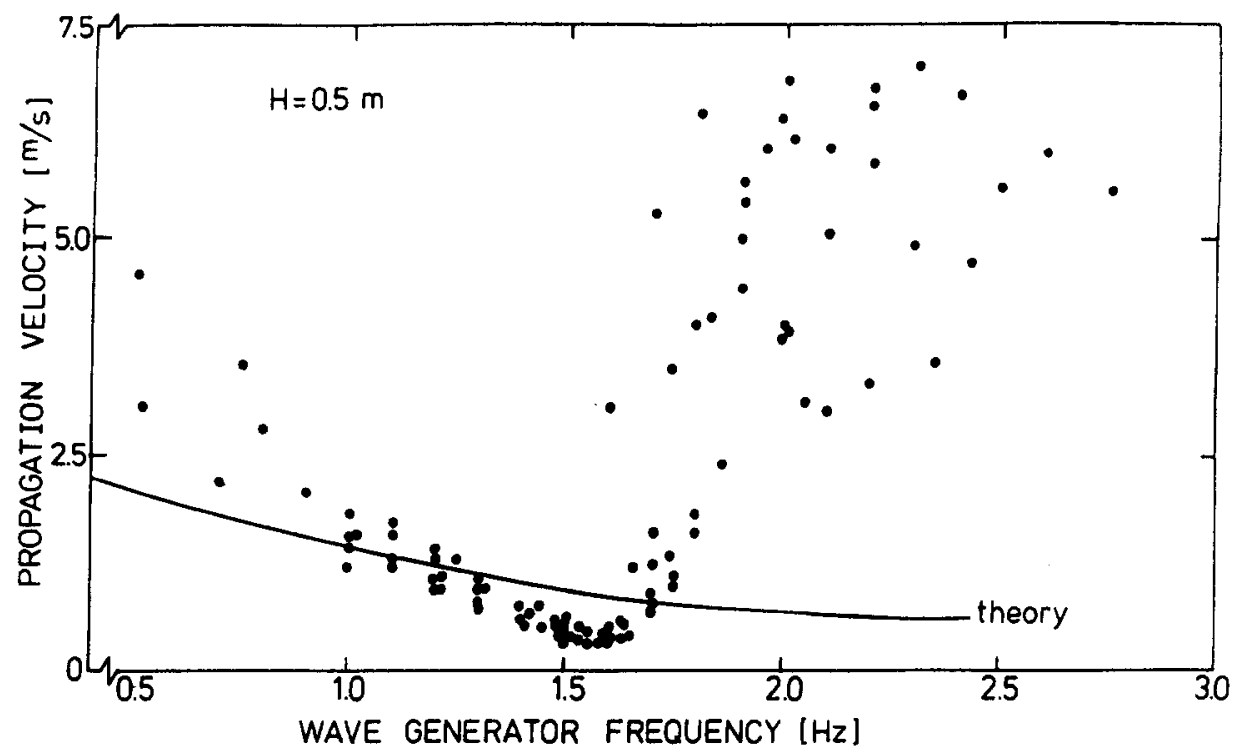

Figure 4. Propagation velocity of the pressure fluctuations as a function of the wave generator frequency in a bed with $H=0.5 \mathrm{~m}$.

\section{RESULTS}

In this section the measured propagation velocities and rates of attenuation of the induced pressure fluctuations will be discussed. By comparison with the theory for surface waves on a liquid, the effective viscosity will be determined.

\subsection{Propagation velocity}

The propagation velocity of the induced pressure fluctuations measured as a function of the wave generator frequency in a bed with height $0.5 \mathrm{~m}$ is shown in figure 4 . The horizontal plate amplitude at the surface was $20 \mathrm{~mm}$ and the vertical distance from the measurement points to the distributor was $0.3 \mathrm{~m}$. It is seen that at low wave generator frequencies the propagation velocity of surface waves decreases from $3 \mathrm{~m} / \mathrm{s}$ at $0.5 \mathrm{~Hz}$ to $0.3 \mathrm{~m} / \mathrm{s}$ at $1.6 \mathrm{~Hz}$. In this frequency range, the measurement

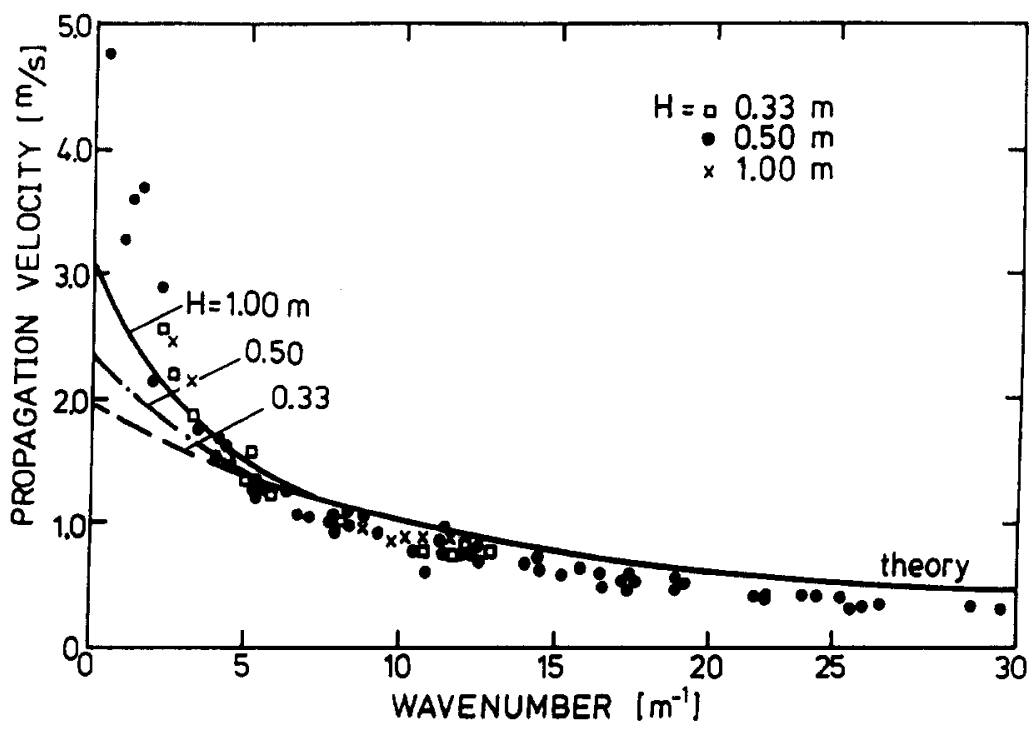

Figure 5. Propagation velocity of surface waves as a function of the wavenumber. 
points follow the theoretical curve for surface waves reasonably well. At low frequencies $(f<1.0 \mathrm{~Hz})$ the measured wave velocity is higher than predicted.

At frequencies $>1.6 \mathrm{~Hz}$, the propagation velocity increases from $0.3 \mathrm{~m} / \mathrm{s}$ at $1.6 \mathrm{~Hz}$ to $7 \mathrm{~m} / \mathrm{s}$ at $2.5 \mathrm{~Hz}$. These measured wave velocities do not correlate with the theory. Apparently, at $1.6 \mathrm{~Hz} \mathrm{a}$ transition occurred in the type of waves generated. Above $1.6 \mathrm{~Hz}$, high-pressure fluctuations were measured without significant bed elevation. Instead of surface waves, density waves were propagating. Obviously, the assumption of constant particle concentration is not allowed at these operating conditions. Joseph (1991) suggested that the change in behaviour above $1.6 \mathrm{~Hz}$ was due to off-design operation of the wave generator. At high frequencies the horizontal velocity of the generator's flat plate will exceed the local velocity induced by the surface wave; in such cases, a density wave will be generated.

In figure 5 the propagation velocity is displayed as a function of the wavenumber. Only measurement points obtained with wave generator frequencies $<1.6 \mathrm{~Hz}$ were used. Figure 5 shows that the propagation velocity is well-predicted by the surface wave theory for wavenumbers from 5 to $30 \mathrm{~m}^{-1}$. For wavenumbers $<5 \mathrm{~m}^{-1}$, there is less agreement. Similar results were obtained at bed heights of 0.33 and $1.0 \mathrm{~m}$.

\subsection{Rate of attenuation}

Figure 6 shows the spatial rate of attenuation $\left(\mathrm{LD}_{x}\right)$ of the pressure fluctuations as a function of frequency. The measured $L D_{x}$ is displayed together with the values predicted ([A4] and [A5]) for three different effective viscosities with a bed depth of $0.5 \mathrm{~m}$. Figure 6 shows, in the frequency range 1.0-1.6 Hz, good correlation of the measured and predicted values of $\mathrm{LD}_{x}$ for an effective kinematic shear viscosity $v=\mu /\left(\rho_{\mathrm{p}} \alpha\right)$ between $5 \times 10^{-3}$ and $10^{-2} \mathrm{~m}^{2} / \mathrm{s}$. In the frequency range $0.5-1.0 \mathrm{~Hz}$, measuring the rate of attenuation is troublesome due to the low damping of waves at those frequencies. Above $1.6 \mathrm{~Hz}$, the rate of attenuation drops to a constant value of $\mathrm{LD}_{x}=2.5 \mathrm{~m}^{-1}$. Obviously this is the $\mathrm{LD}_{x}$ of a density wave.

At bed heights of 0.33 and $1.0 \mathrm{~m}$, similar results were obtained. The appropriate viscosity is between $2 \times 10^{-3}$ and $5 \times 10^{-3} \mathrm{~m}^{2} / \mathrm{s}$. The $\mathrm{LD}_{x}$ drops above $1.6 \mathrm{~Hz}$ to constant values of 2.8 and $6.1 \mathrm{~m}^{-1}$ at bed heights of 0.33 and $1.0 \mathrm{~m}$, respectively.

Concluding, the kinematic shear viscosity can be estimated between $2 \times 10^{-3}$ and $10^{-2} \mathrm{~m}^{2} / \mathrm{s}$ and the dynamic shear viscosity between 1.2 and $6 \mathrm{~Pa} \cdot \mathrm{s}$. According to Davidson et al. (1977), "a reasonable estimate for the viscosity of an ordinary fully fluidized bed may be put at about 10 poise" $(=\mathrm{Pa} \cdot \mathrm{s})$. They base this on bubble shape experiments by Grace (1970) and Couette viscometer experiments by Schügerl et al. (1961) with particles of diameter $220-500 \mu \mathrm{m}$. This value cited in literature agrees with our estimation of the dynamic shear viscosity.

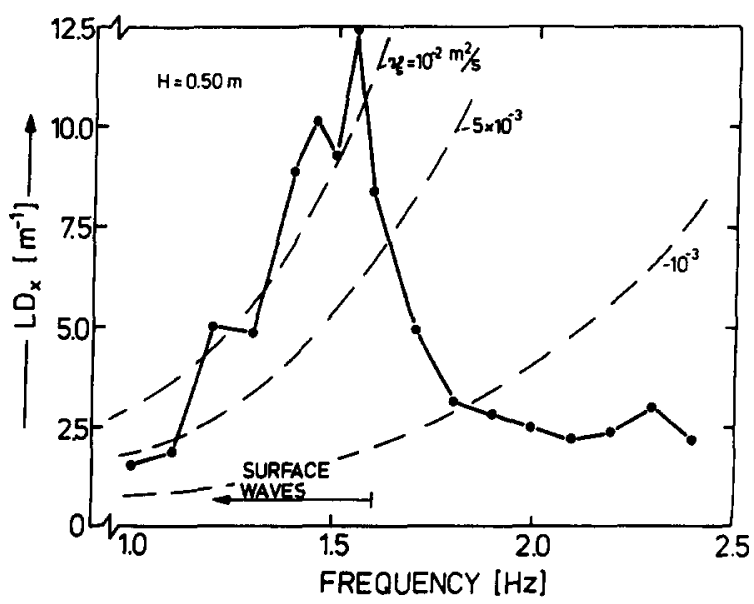

Figure 6. Rate of attenuation of the pressure fluctuations as a function of the wave generator frequency in a bed with $H=0.5 \mathrm{~m}$.

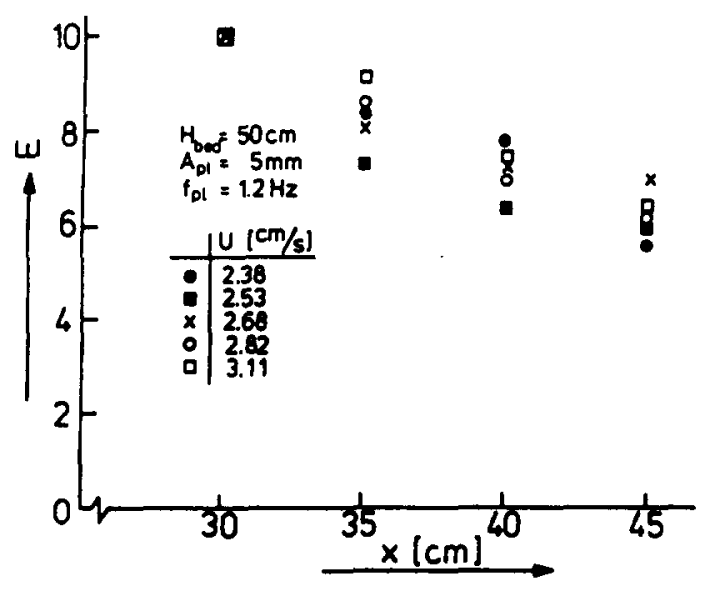

Figure 7. Normalized value of the measured energy density of the pressure fluctuations as a function of distance and at various fluidization velocities; frequency $=1.2 \mathrm{~Hz}$, bed height $=0.5 \mathrm{~m}$. 
Recently, Brinkert \& Davidson (1993) determined the viscosity by measuring the profile of a particle jet in a fluidized bed. For silica-alumina particles with a diameter of $70 \mu \mathrm{m}$, the viscosity measured was about $0.3-0.5 \mathrm{~Pa} \cdot \mathrm{s}$. Schüger et al. (1961) found, for silver sand with particle diameter $72 \mu \mathrm{m}$, a comparable value of the viscosity of $0.5 \mathrm{~Pa} \cdot \mathrm{s}$. It can be concluded that the viscosity measurements, like the bubble shape, the particle jet and the surface wave method, lead to similar results for the viscosity.

The effect of the fluidization velocity on the results above was investigated by increasing the air velocity from 2.4 to $3.11 \mathrm{~cm} / \mathrm{s}$, well above the minimum bubbling velocity. This did not have a measurable effect on the propagation speed of rate of attenuation of the surface waves. In order to illustrate this, the normalized value of the measured energy density of the pressure fluctuations as a function of distance and at various fluidization velocities is shown in figure 7 . This shows clearly that (a) the results do not change if the bed regime is changed from homogeneous to heterogeneous and (b) the energy density of the pressure fluctuations decreases logarithmically with the distance from the wave generator. Hence the measurements are not disturbed by wall reflections.

\section{CONCLUSION}

Surface waves with a wavelength of $0.5-2 \mathrm{~m}$ were generated on a homogeneously fluidized bed. In order to measure the propagation velocity and rate of attenuation of the pressure fluctuations induced by the surface waves at the wave generator frequency, it was necessary to use cross- and auto-spectral density function analyses.

The propagation velocity of surface waves on a homogeneously fluidized bed can be predicted reasonably well with the theory on water waves. This is in agreement with the theory on surface waves on a fluidized bed as developed by Needham (1984). As these are kinematic waves, this conclusion does not lead to a measured material parameter of the bed, like viscosity. The measured propagation velocities vary from $3 \mathrm{~m} / \mathrm{s}$ at $0.5 \mathrm{~Hz}$ to $0.3 \mathrm{~m} / \mathrm{s}$ at $1.6 \mathrm{~Hz}$.

The measured rate of attenuation was compared with the values predicted by the theory on surface waves on an incompressible liquid. Agreement was found for effective dynamic shear viscosities between 1.2 and $6.0 \mathrm{~Pa} \cdot \mathrm{s}$. This is of the same order of magnitude as values cited in the literature.

The results are not affected by a change in the fluidization regime from homogeneous to heterogeneous.

A transition from surface to density waves occurred at a wave generator frequency of $1.6 \mathrm{~Hz}$ due to off-design operation of the wave generator.

Acknowledgement-This research program is executed within the framework of the Dutch National Coal Research Program, financed by the Ministry of Economic Affairs.

\section{REFERENCES}

ANDERson, T. B. \& JACKson, R. 1967 A fluid mechanical description of fluidized beds. Ind. Engng Chem. Fundam. 6, 527-539.

Bendat, J. S. \& Piersol, A. G. 1980 Engineering Applications of Correlation and Spectral Analysis. Wiley, New York.

Biésel, F. \& SuqueT, F. 1951a Les appareils générateurs de houle en laboratoire. Houille Blanche 6, 147-165.

BiÉsel, F. \& Suquet, F. 1951b Les appareils générateurs de houle en laboratoire (suite). Houille Blanche 6, 475-496.

Brinkert, J. \& Davidson, J. F. 1993 Particle jets in fluidised beds. Trans. Instn Chem. Engrs A 71, 334-336.

Davidson, J. F., Harrison, D. \& Guedes de Carvalho, J. R. F. 1977 On the behavior of fluidized beds. A. Rev. Fluid Mech. 9, 55-86.

FAN, L. T., Ho, T.-C. \& WalaWENDER, W. P. 1983 Measurements of the rise velocities of bubbles, slugs and pressure waves in a gas-solid fluidized bed using pressure fluctuation signals. AIChE Jl 29, 33-39. 
Finnerty, R. G., MaA, J. R., Vossler, A. M., Yeh, H. S., Crouse, W. W. \& Rice, W. J. 1969 Waves at surfaces of fluidized beds. Ind. Engng Chem. Fundam. 8, 271-278.

GASTER, M. J. 1963 A note on the relation between temporally increasing and spatially increasing disturbances in hydrodynamic stability. J. Fluid Mech. 14, 222-224.

Grace, J. R. 1970 The viscosity of fluidized beds. Can. J. Chem. Engng 48, 30-33.

JOSEPH, D. D. 1991 Private communication at the IUTAM Symp. on Mechanics of Fluidized Beds, Stanford.

KeUlegaN, G. H. 1959 Energy dissipation in standing waves in rectangular basins. J. Fluid Mech. 6, 33-50.

LighthILL, M. J. 1978 Waves in Fluids. Cambridge University Press, Cambridge, U.K.

NeEDHAM, D. J. 1984 Surface waves on a homogeneously fluidized bed. J. Engng Math. 18, 259-271.

RICE, W. J. \& WILHELM, R. H. 1958 Dynamics of fluidized beds and quality of fluidization. AIChE $J l$ 4, 423-430.

SCHÜGERL, K., MERz, M. \& FetTing, F. 1961 Rheologische eigenschaften von gasdurchströmten fliessbettsystemen. Chem. Engng Sci. 15, 39.

\section{APPENDIX}

The well-known results for the propagation of surface waves with small amplitudes on a liquid are summarized here. Waves will be studied that are propagating in the $x$-direction with surface elevation $\eta(x, t)$, amplitude $a$, radial frequency $\omega$, wavelength $\lambda$ and wavenumber $k=2 \pi / \lambda$ $(a / \lambda \ll 1)$ :

$$
\eta(x, t)=a \cdot \cos (k x-\omega t) \quad \mathrm{m} .
$$

In a bed with depth $H$ these waves propagate with velocity

$$
V=\frac{\omega}{k}=\left[\frac{g \cdot \tanh (k H)}{k}\right]^{1 / 2} \quad \mathrm{~m} / \mathrm{s}
$$

These waves induce periodic pressure fluctuations $P$ in the bed at a distance $z$ from the bottom, given by

$$
P=a \cdot \rho_{\mathrm{p}} \cdot \alpha \frac{\cosh (k z)}{\cosh (k H)} \cdot \cos (k x-\omega t) \quad \mathrm{N} / \mathrm{m}^{2} .
$$

Possible dissipative mechanisms are assumed to have effects analogous to those on surface waves on an incompressible liquid. A term $\mu \cdot \Delta v$ is introduced in the particle momentum-conservation equation. An effective dynamic shear viscosity of the bed is then defined by $\mu$. In Lighthill (1978) or Keulegan (1959) it is shown that the logarithmic decrement in time $\left(\mathrm{LD}_{t}\right)$ of waves propagating on the surface of an incompressible liquid is

$$
\mathrm{LD}_{t}=\frac{2 \cdot \mu \cdot k^{2}}{\alpha \cdot \rho_{\mathrm{p}}}+\sqrt{\frac{2 \cdot \mu \cdot \omega}{\alpha \cdot \rho_{\mathrm{p}}}} \cdot\left[\frac{1}{B}+\frac{k}{\sinh (2 k H)}\right] \mathrm{s}^{-1} .
$$

The first right-hand term of [A4] is due to the viscous forces influencing the motion of the main body of the bed. The first term in the square brackets is introduced because of the fact that the bed has a finite width $(B)$ with a boundary layer at the two side walls. The second term represents the action of the viscous forces in the boundary layer at the bottom of the bed.

In the experiments it was only possible to measure the spatial logarithmic decrement $L D_{x}$. But from Gaster (1963), it is known that the relation between $\mathrm{LD}_{t}$ and $\mathrm{LD}_{x}$ is

$$
\operatorname{LD}_{x}=\mathrm{LD}_{t}\left(\frac{\partial \omega}{\partial k}\right)^{-1} \mathrm{~m}^{-1}
$$

Using [A4] and [A5] the spatial logarithmic decrement $\mathrm{LD}_{x}$ is found as a function of $\omega$ and $k$ with parameters $\alpha, \rho_{\mathrm{p}}, \mu, B$ and $H$. The former three parameters are combined into a single parameter, the effective kinematic viscosity $v=\mu /\left(\alpha \rho_{\mathrm{p}}\right)$. 